\title{
Characteristics of dairy calf ranches: Morbidity, mortality, antibiotic use practices, and biosecurity and biocontainment practices
}

\author{
W. L. Walker, ${ }^{* 1}$ W. B. Epperson,† T. E. Wittum, ${ }^{\star}$ L. K. Lord, ${ }^{*}$ P. J. Rajala-Schultz, ${ }^{\star}$ and J. Lakritzł \\ *Department of Veterinary Preventive Medicine, College of Veterinary Medicine, The Ohio State University, Columbus 43210 \\ †Department of Pathobiology and Population Medicine, College of Veterinary Medicine, Mississippi State University, Mississippi State 39762 \\ $\ddagger$ Department of Veterinary Clinical Sciences, College of Veterinary Medicine, The Ohio State University, Columbus 43210
}

\section{ABSTRACT}

The utilization of farming operations specializing in rearing dairy heifer calves has increased since the early 1990s. However, these operations have not been as well characterized as US dairy operations with respect to demographic and health-related measures, particularly during the preweaning period. The objective of this study was to characterize morbidity, mortality, antibiotic use, and biosecurity and biocontainment practices on operations rearing preweaned heifers only or preweaned heifer and bull calves (mixed) in the United States. A cross-sectional survey was performed using a standardized method that included a preletter, initial survey, postcard follow-up, and second survey delivered by mail. Additional follow-up contacts were attempted by telephone. Descriptive statistics for morbidity, mortality, antibiotic use, and biosecurity and biocontainment practices were computed at both the operation and calf levels. The overall response rate was $50 \%$. Crude yearly mortality averaged $6.9 \%$ at the calf level, with the median operation reporting $3.6 \%$ mortality. Diarrhea was experienced by $18 \%$ of calves, with $73 \%$ receiving an antibiotic. The median operation reported $20 \%$ diarrhea morbidity with $83 \%$ receiving an antibiotic. Respiratory disease was experienced by $9.0 \%$ of calves, with $82 \%$ receiving an antibiotic. The median operation reported $5.3 \%$ respiratory morbidity, with $100 \%$ receiving an antibiotic. Heifer-only and mixed operations did not differ in operation median morbidity, mortality, or antibiotic treatment rates. Written antibiotic protocols were available on $65 \%$ of operations. Medicated milk replacer was used by $56 \%$ of operations. Passive immunity was routinely measured by $46 \%$ of operations. Direct contact between calves in housing units was not allowed by $45 \%$ of operations. Of all farms informed of disease concerns at the source farm, $76 \%$ changed their

Received July 14, 2011.

Accepted November 19, 2011.

${ }^{1}$ Corresponding author: doc4vacas@gmail.com daily routine as a result. Almost all operations uniquely identified calves and recorded mortality. The heiferonly and mixed operations in this study were similar to US dairy operations for key health, antibiotic use, and biosecurity and biocontainment metrics. This research provides initial estimates of key demographics usable by calf ranches, veterinarians, and other professionals serving this segment of the US dairy industry.

Key words: dairy, calf ranch, morbidity, mortality

\section{INTRODUCTION}

Financial concerns, consolidation, increasing herd size, and greater emphasis on the production of saleable milk have fueled the growth of farming operations specializing in rearing dairy replacement heifers (Wolf, 2003). Since the early 1990s, the percentage of US dairy operations utilizing specialized contract heifer rearing facilities to develop replacement heifers has increased almost 3-fold from 1.6 to $4.6 \%$, currently representing $11.5 \%$ of the US dairy heifer population (USDA, 1993, 2007). These specialized operations are commonly referred to as "calf ranches," "heifer ranches," or "custom heifer growers," and are generally located apart from the source dairy.

When choosing whether to utilize a calf ranch or when selecting a specific calf ranch, several factors may be considered, such as economics, morbidity, mortality, antibiotic use practices, and biosecurity practices. To date, few studies of calf ranches have reported this type of information for the entire calf ranch industry. One report describes basic operation characteristics, contract terms, and management practices, but morbidity, mortality, antibiotic use, and an in-depth examination of preweaning calf biosecurity practices were not within the scope of the study (Wolf, 2003). However, this study found that $83 \%$ of custom heifer growers raised heifers for multiple clients (Wolf, 2003), a finding that underscores the importance of knowing biosecurity and other management practices relevant to preventing transmission of disease. Other studies have investigated mortality on heifer and dairy-beef calf ranches rearing 
preweaned calves but each was limited to a single calf ranch (Tyler et al., 1998; Moore et al., 2002).

Clearly, the need exists for a broad-based demographic survey of calf health metrics, antibiotic use, and biosecurity and biocontainment on calf ranches in the United States. Industry-wide data will provide initial benchmark estimates for use by calf ranches, dairy farms, and their advisors. Accordingly, the overall objectives of this study were to describe herd demographics, health metrics, antibiotic use practices, and biosecurity and biocontainment practices on calf ranches rearing preweaned calves in 2006 and to evaluate the relationships among morbidity, mortality, antibiotic use practices, and biosecurity and biocontainment practices on these calf ranches. The specific objective of this report was to characterize morbidity, mortality, antibiotic use practices, and biosecurity and biocontainment practices. Future reports will examine the relationship of morbidity and mortality to both antibiotic use practices and biosecurity and biocontainment practices.

\section{MATERIALS AND METHODS}

\section{Study Population}

The study population consisted of a convenience sample of operations believed to be engaged in rearing of preweaned dairy heifer or heifer and bull calves within the United States. Sources of contact information included the membership roster of the Dairy Calf and Heifer Association (DCHA, Chesterfield, MO), personal contacts of the authors, and freely accessible websites. A calf ranch was considered as an operation raising someone else's preweaned heifer or bull calves alone or in addition to raising his or her own calves.

\section{Sampling Frame}

The overarching goal of the sampling frame was to be maximally inclusive because no single list of calf ranches in the United States was available. The sampling frame was initially constructed from the DCHA membership roster by extracting all known calf ranches and including all other members of unknown status. The sampling frame was augmented with contact information from calf ranches identified by personal contacts of the authors and contact information obtained from freely accessible websites using the search terms "heifer" and "calf." Entries were excluded immediately if it was known from personal or contact information that they were not calf ranches. After removing duplicate entries, the total sampling frame included 416 potential calf ranches representing 37 states and 1 US territory.

\section{Study Design}

A cross-sectional study was performed with a mail survey data collection scheme. The mail survey was conducted according to a standardized survey methodology (Dillman, 2007). In June 2007, potential respondents received a preemptive letter explaining the purpose of the survey with notification to expect a survey packet. One week later, the survey packet containing the questionnaire and a cover letter was mailed. Two weeks after the initiation of the survey, a postcard reminder was sent thanking respondents and encouraging those not yet responding to do so. Four weeks after study initiation, a second survey packet with a different cover letter was mailed to nonrespondents. Attempts to contact nonrespondents via telephone were made 7, 9, and $13 \mathrm{wk}$ after initiation of the survey. Additional potential respondents identified during the course of the study underwent similar survey procedures beginning as soon as possible after those growers were identified. Attempts were made to contact respondents with ambiguous or uninterpretable responses and to determine eligibility status when unknown.

Respondents and nonrespondents were categorized into regions analogous to a previous survey with arbitrary modifications to accommodate additional states (USDA, 2002). Regions and their associated states were as follows: West: Arizona, California, Idaho, Kansas, North Dakota, New Mexico, Oklahoma, Oregon, South Dakota, Texas, Washington, and Wyoming; Midwest: Illinois, Indiana, Iowa, Michigan, Minnesota, Missouri, Ohio, and Wisconsin; Northeast: Massachusetts, New York, Pennsylvania, and Vermont; and Southeast: Florida, Georgia, Kentucky, Maryland, North Carolina, Tennessee, and Virginia.

\section{Mail Questionnaire}

Calf growers were asked 54 questions regarding operation-level demographics, morbidity, mortality, herdlevel policies and estimates for antibiotic usage, and herd-level policies for biosecurity and biocontainment during 2006. To facilitate comparability with US dairy operations, some questions were adapted from previous surveys conducted by the USDA's National Animal Health Monitoring System (USDA, 1993, 1994, 1996, $2002,2007)$. Questions on herd demographics included the number of preweaned calves reared in 2006, average age at weaning, and liquid feeding policies. Questions regarding disease demographics included estimates of number of calves experiencing crude and diseasespecific (diarrhea or respiratory disease) morbidity or mortality, antibiotic-use policy, and availability of 
written records and treatment protocols. All morbidity and mortality data were self-reported estimates. Nutritional demographic questions included primary source of milk, feeding methods, and whether nutrient content was increased during certain seasons of the year. An increase in one or more of the following was considered increased nutrient content: volume, amount of powder for milk replacers, or percentage of $\mathrm{CP}$ or crude fat. Seasons were defined as follows: spring = March, April, and May; summer = June, July, and August; fall = September, October, and November; and winter = December, January, and February. Respondents were asked to report individual calf-level management and health data, including the use of unique identification, mortality, morbidity, disease treatments, and passive immunity status.

Respondents were asked questions regarding the use of various biosecurity and biocontainment practices during 2006, with answers typically dichotomized as yes or no. Biosecurity was defined as "any measures taken to help prevent disease from being introduced to your farm" and biocontainment was defined as "any measures taken to help prevent the spread of disease within your farm." Questions focused on the use of generally accepted biosecurity or biocontainment practices, including sanitation, transportation policies, use of personal protective equipment, assessment of direct contacts, and communication with the source dairy. Each respondent was asked to rate his or her perception of current biosecurity and biocontainment policies on a 4-level ordinal scale from "poor" to "excellent." Each respondent was asked to enumerate his or her perception of the risk engendered by various personnel potentially encountered by a calf ranch on a 5-level ordinal scale from "low" to "high" with an additional category of "not applicable" (NA) for personnel not encountered on a given operation.

Two veterinarians familiar with the calf rearing industry, a university dairy scientist, and 2 calf ranchers reviewed potential questions before the final questionnaire was constructed. All survey results were entered into an Access 2007 database (Microsoft Corp., Redmond, WA) upon receipt. The survey was granted exempt status after review by The Ohio State University Institutional Review Board.

\section{Statistical Analysis}

Estimates of the number of calves experiencing morbidity, mortality, and antibiotic treatment were used as the numerator for computing operation-level proportions as needed for descriptive statistics and modeling purposes. Additionally, and for descriptive comparison, morbidity, mortality, and antibiotic-use estimates were weighted by ranch size to yield calf-level estimates of all operations. Responses to operation-level policy questions and numerical estimates were categorized as needed to facilitate description and analysis. Descriptive statistics and computations for continuous variables were reported at the operation-level as a median and inter-quartile range, and categorical variables were reported as proportions in tabular format. Calf-level estimates were computed as a weighted mean. Formal statistical analyses were conducted for operations rearing only preweaned heifer calves (HC) and those rearing both preweaned heifer and preweaned bull calves (MC). Operations rearing only preweaned bull calves $(\mathrm{n}=18, \mathbf{B C})$ were excluded from descriptive statistics and statistical analyses because the sample consisted of too few observations to be considered representative. For descriptive statistics, antibiotic treatment rates were expressed as a proportion of cases of a given disease. Continuous operation-level demographic variables were compared using the median test and binary demographic variables compared with a 2-sample proportion test. Univariable associations between categorical variables and $\mathrm{HC}$ or MC operations were assessed with Chi-square tests or Fisher's exact test. The overall type I error rate was protected across multiple comparisons using a Bonferroni-corrected $P$-value. All descriptive statistics and analyses were generated in Stata/IC 10.1 (2009; StataCorp LP, College Station, TX).

\section{RESULTS AND DISCUSSION}

In total, 416 initial surveys were distributed to potential respondents. Of the 416 potential respondents, 204 reported not raising preweaned calves for sale or return to the source dairy and were ineligible for the study. Of the 212 eligible potential $\mathrm{HC}, \mathrm{BC}$, and $\mathrm{MC}$ respondents, 105 usable responses were received, yielding a $50 \%$ response rate. The distribution of responses for HC and MC operations was Midwest 49\%, Northeast $24 \%$, West $18 \%$, and Southeast $9.0 \%$. The response rate for $\mathrm{HC}$ and $\mathrm{MC}$ operations ranged from $84 \%$ in the Northeast to $28 \%$ in the West. We were unable to ascertain what influence the distribution of responses or the distribution of nonrespondents in each region had on our estimates because no other estimates were available for this population, the population distribution of calf ranches has not been enumerated, and little information was available on nonresponders to facilitate comparison with responders.

\section{Demographic and Nutritional Characteristics}

The median number of preweaned calves reared in 2006 was 450, with a range of 14 to 100,000 (Table 1 ). 
Table 1. Operation-type-specific demographics of preweaned calf rearing operations in 2006

\begin{tabular}{|c|c|c|c|c|c|c|}
\hline \multirow[b]{2}{*}{ Operation type $^{1}$} & \multirow[b]{2}{*}{$\mathrm{n}^{2}$} & \multicolumn{5}{|c|}{ Percentile } \\
\hline & & Median & Minimum & 25 th & 75 th & Maximum \\
\hline \multicolumn{7}{|l|}{$\mathrm{HC}$} \\
\hline Total number of calves & 48 & $301^{\mathrm{b}}$ & 14 & 93 & 1,241 & 32,190 \\
\hline Arrival age (d) & 48 & $3^{\mathrm{a}}$ & 1 & 2 & 5 & 10 \\
\hline Weaning age $(\mathrm{d})$ & 48 & $49^{\mathrm{a}}$ & 35 & 41 & 53 & 90 \\
\hline \multicolumn{7}{|l|}{$\mathrm{MC}$} \\
\hline Total number of calves & 38 & $750^{\mathrm{a}}$ & 20 & 300 & 8,897 & 100,000 \\
\hline Arrival age (d) & 38 & $2^{\mathrm{b}}$ & 1 & 1 & 5 & 25 \\
\hline Weaning age $(\mathrm{d})$ & 39 & $45^{\mathrm{a}}$ & 27 & 42 & 60 & 90 \\
\hline \multicolumn{7}{|l|}{ Overall } \\
\hline Total number of calves & 86 & 450 & 14 & 120 & 2,200 & 100,000 \\
\hline Arrival age $(d)$ & 86 & 3 & 1 & 2 & 5 & 25 \\
\hline Weaning age $(\mathrm{d})$ & 87 & 48 & 27 & 42 & 56 & 90 \\
\hline
\end{tabular}

The HC operations reared fewer calves $(\mathrm{n}=301)$ than MC operations $(\mathrm{n}=750, P=0.018)$. Of all preweaned calves reared on MC operations, a median of $73 \%$ were heifers and $27 \%$ bulls. The median MC operation reported receiving calves at $2 \mathrm{~d}$ of age, whereas $\mathrm{HC}$ operations received calves at $3 \mathrm{~d}$ of age $(P=0.030)$. The median age at weaning was $48 \mathrm{~d}$ with a range of 27 to $90 \mathrm{~d}$. The HC operations $(\mathrm{n}=48)$ represented 74,274 calves, and MC operations $(\mathrm{n}=38)$ represented 397,501 calves.

The primary source of liquid nutrition during the preweaning period on 45 of $48(94 \%) \mathrm{HC}$ and 27 of 39 (69\%) MC operations was milk replacer $(P=0.003)$. In comparison, $68.6 \%$ of US dairy operations report using at least some milk replacer (USDA, 2008b). Most $\mathrm{HC}$ and $\mathrm{MC}$ operations (56 of 86, 65\%) had a policy of feeding calves according to more "traditional" methods of $20 \% \mathrm{CP}, 20 \%$ crude fat milk replacer, or whole milk fed at a rate of 1 gallon per day. The majority of operations (70 of $86,81 \%$ ) had a policy of purposefully increasing the nutrient content of liquid feeds at some point during the year, with this increase occurring more often during winter than in other seasons $(P<0.005)$.

\section{General Morbidity and Mortality}

Overall operation-level median preweaning mortality was $3.6 \%$ (Table 2). The HC operations had a median $3.0 \%$ mortality, somewhat lower than the $4.3 \%$ herdspecific median crude mortality reported in a study of New York State dairy operations (Virtala et al., 1996c). On a calf-level basis, mortality on HC operations averaged $5.4 \%$, slightly lower than the $7.8 \%$ estimated for heifer calves on US dairy operations in 2006 (USDA, 2007 ), lower than the $7.9 \%$ reported on a single heifer- rearing facility over $10 \mathrm{yr}$ (Tyler et al., 1998), and less than the 4-wk mortality of $13 \%$ on a Holstein bull-calf beef operation (Moore et al., 2002). Our results suggest that the overall calf mortality experience on surveyed calf ranches was not different from common conventional metrics.

Overall operation-level median diarrhea morbidity was $20 \%$ with $1.2 \%$ mortality because of diarrhea (Table 2). The median HC operation reported $22 \%$ diarrhea morbidity, the same as was found in another study of dairy operations (Virtala et al., 1996c). At the calf level, HC diarrhea morbidity averaged $43 \%$ and diarrhea mortality averaged $4.1 \%$. Comparable cross-sectional studies of preweaned heifer calves on US dairy operations reported diarrhea morbidity of $23.9 \%$ (USDA, 2008a) and mortality of $4.4 \%$ (computed from available USDA statistics) in 2006 (USDA, 2007). Prospective estimates for the US dairy industry indicated that $27.2 \%$ of heifer calves experienced diarrhea in the first 8 wk of life (USDA, 1994). Others have reported diarrhea morbidity of $15.2 \%$ in heifer calves up to 16 wk of age (Sivula et al., 1996) and $35 \%$ up to 6 mo of age (Donovan et al., 1998). The operation median morbidity in this survey approximated the US national average, indicating that surveyed ranches had a similar experience to the national average. The calf-level morbidity observed here was influenced by higher morbidity in one larger ranch. However, no overall trend associating morbidity or mortality with ranch size was apparent. Overall, diarrhea morbidity and mortality experience across responding $\mathrm{HC}$ and $\mathrm{MC}$ operations corresponded to that of US dairy operations.

The HC and MC operations reported median respiratory morbidity of $5.3 \%$ and mortality of $0.47 \%$ (Table 2 ), similar to another study reporting median herd-spe- 
Table 2. Operation-type-specific yearly and disease-specific demographics of preweaned calf rearing operations in 2006

\begin{tabular}{|c|c|c|c|c|}
\hline \multirow[b]{2}{*}{ Operation type $^{1}$} & \multirow[b]{2}{*}{$\mathrm{n}^{2}$} & \multicolumn{3}{|c|}{ Percentile } \\
\hline & & Median & 25 th & 75 th \\
\hline \multicolumn{5}{|l|}{$\mathrm{HC}$} \\
\hline Yearly mortality (\%) & 47 & 3.0 & 1.2 & 5.3 \\
\hline Diarrhea morbidity $(\%)$ & 47 & 22 & 10 & 36 \\
\hline Diarrhea mortality (\%) & 48 & 1.0 & 0.22 & 2.5 \\
\hline Respiratory morbidity (\%) & 46 & 5.7 & 1.8 & 10 \\
\hline Respiratory mortality (\%) & 46 & 0.35 & 0.0 & 1.0 \\
\hline \multicolumn{5}{|l|}{ MC } \\
\hline Yearly mortality (\%) & 35 & 4.5 & 2.5 & 6.7 \\
\hline Diarrhea morbidity (\%) & 31 & 19 & 6.7 & 40 \\
\hline Diarrhea mortality (\%) & 33 & 1.4 & 0.33 & 4.0 \\
\hline Respiratory morbidity (\%) & 31 & 5.0 & 2.0 & 12 \\
\hline Respiratory mortality (\%) & 34 & 0.84 & 0.14 & 1.7 \\
\hline \multicolumn{5}{|l|}{ Overall } \\
\hline Yearly mortality (\%) & 82 & 3.6 & 1.9 & 5.7 \\
\hline Diarrhea morbidity $(\%)$ & 78 & 20 & 9.1 & 36 \\
\hline Diarrhea mortality (\%) & 81 & 1.2 & 0.32 & 3.2 \\
\hline Respiratory morbidity (\%) & 77 & 5.3 & 2.0 & 11 \\
\hline Respiratory mortality (\%) & 80 & 0.47 & 0.0 & 1.3 \\
\hline
\end{tabular}

cific respiratory morbidity of 4.0 to $20 \%$ (Virtala et al., 1996b). At the calf level, HC operations in our study averaged $17 \%$ respiratory morbidity and $1.0 \%$ respiratory mortality. In 2006, preweaned heifer calves on US dairy operations had an estimated $12.4 \%$ respiratory morbidity (USDA, 2008a) and $1.8 \%$ mortality (computed from available USDA statistics; USDA, 2007). Prospective estimates for US dairy heifer calves found that $8.9 \%$ experienced respiratory disease in the first 8 wk of life (USDA, 1994), whereas other studies suggest that between $7.6 \%$ (Sivula et al., 1996) and $21 \%$ of heifer calves experience respiratory disease (Donovan et al., 1998). Although the median level of respiratory disease and death was less than the overall US average, the calf-level descriptors again indicated a greater disease burden in larger operations in this survey.

Case fatality rate, a measure of diagnostic and treatment intervention effectiveness, was a median $7.7 \%$ for diarrhea at the operation level and $6.7 \%$ for $\mathrm{HC}$ operations, which is comparable to $7.6 \%$ median herdspecific case fatality for diarrhea in dairy operations (Virtala et al., 1996c). At the calf level, the case fatality rate for diarrhea was $11 \%$ for $\mathrm{HC}$ operations. Our estimate for calves on $\mathrm{HC}$ operations was in accord with prospective case fatality estimates for diarrhea in heifer calves that ranged from 7.7\% (Donovan et al., 1998) to $17.9 \%$ (Sivula et al., 1996). Median case fatality rate for respiratory disease was $9.0 \%$ at the operation level. At the calf level, respiratory disease case fatality rate was $7.5 \%$ for calves on $\mathrm{HC}$ operations. Our estimates are in line with prospective estimates of respiratory disease case fatality of $9.4 \%$ (Sivula et al., 1996) and 13.8\% (Donovan et al., 1998). Overall, our case fatality results suggest interventional success comparable to that of dairy operations.

A median of $50 \%$ of all deaths was attributed to diarrhea on $\mathrm{HC}$ and $\mathrm{MC}$ operations. At the calf level, $\mathrm{HC}$ operations in the present study had $63 \%$ of all mortality attributable to diarrhea, whereas on US dairy operations, $56.5 \%$ of all heifer calf mortality was attributed to scours, diarrhea, or other digestive problems in 2006 (USDA, 2007). Still lower, another study estimated that only $43.8 \%$ of heifer deaths were due to diarrhea ( $\mathrm{Si}$ vula et al., 1996). The HC and MC operations reported a median $19 \%$ of all mortality attributed to respiratory disease. At the calf level, $\mathrm{HC}$ operations averaged $20 \%$ of all mortality attributed to respiratory disease, whereas in 2006, heifer calves on US dairy operations had an estimated $22.5 \%$ of all mortality attributed to respiratory disease (USDA, 2007); another study found that $29.7 \%$ of deaths were due to respiratory disease (Sivula et al., 1996).

Our results suggest that calves reared on $\mathrm{HC}$ and $\mathrm{MC}$ calf ranches have values for common health metrics at least equivalent to those of calves reared on an "average" US dairy operation. However, the median calf-level estimates suggest improved calf health compared with national metrics. The population of calf ranches in this survey was very diverse with respect to the number of calves reared. Some differences that exist between 
Table 3. Operation-type-specific diarrhea and respiratory disease antibiotic treatment demographics of preweaned calf rearing operations in 2006

\begin{tabular}{|c|c|c|c|c|}
\hline \multirow[b]{2}{*}{ Operation type ${ }^{1}$} & \multirow[b]{2}{*}{$\mathrm{n}^{2}$} & \multicolumn{3}{|c|}{ Percentile } \\
\hline & & Median & 25 th & 75 th \\
\hline \multicolumn{5}{|l|}{$\mathrm{HC}$} \\
\hline Diarrhea antibiotic treatment rate $^{3}(\%)$ & 45 & 83 & 35 & 100 \\
\hline Diarrhea multiple antibiotic treatment rate $^{4}(\%)$ & 42 & 35 & 2.2 & 86 \\
\hline Respiratory antibiotic treatment rate $(\%)$ & 40 & 100 & 100 & 100 \\
\hline Respiratory multiple antibiotic treatment rate $^{6}(\%)$ & 41 & 33 & 0.0 & 60 \\
\hline \multicolumn{5}{|l|}{1} \\
\hline Diarrhea antibiotic treatment rate $(\%)$ & 28 & 85 & 10 & 100 \\
\hline Diarrhea multiple antibiotic treatment rate $(\%)$ & 23 & 67 & 14 & 100 \\
\hline Respiratory antibiotic treatment rate $(\%)$ & 24 & 100 & 100 & 100 \\
\hline Respiratory multiple antibiotic treatment rate (\%) & 26 & 50 & 19 & 100 \\
\hline \multicolumn{5}{|l|}{ Overall } \\
\hline Diarrhea antibiotic treatment rate $(\%)$ & 73 & 83 & 30 & 100 \\
\hline Diarrhea multiple antibiotic treatment rate $(\%)$ & 65 & 50 & 8.0 & 100 \\
\hline Respiratory antibiotic treatment rate $(\%)$ & 64 & 100 & 100 & 100 \\
\hline Respiratory multiple antibiotic treatment rate $(\%)$ & 67 & 47 & 7.1 & 100 \\
\hline \multirow{2}{*}{\multicolumn{5}{|c|}{${ }^{1}$ Operation type: $\mathrm{HC}=$ preweaned heifer calves only; $\mathrm{MC}=$ preweaned heifer and bull calves. }} \\
\hline & \multicolumn{4}{|c|}{${ }^{2} \mathrm{n}=$ number of respondents for a given question. } \\
\hline \multicolumn{5}{|c|}{${ }^{3}$ Proportion of calves with diarrhea that were treated with an antibiotic. } \\
\hline \multirow{2}{*}{\multicolumn{5}{|c|}{$\begin{array}{l}{ }^{4} \text { Proportion of calves with diarrhea treated with an antibiotic that received more than one type of antibiotic. } \\
{ }^{5} \text { Proportion of calves with respiratory disease that were treated with an antibiotic. }\end{array}$}} \\
\hline & & & & \\
\hline \multicolumn{5}{|c|}{$\begin{array}{l}{ }^{6} \text { Proportion of calves with respiratory disease treated with an antibiotic that received more than one type } \\
\text { antibiotic. }\end{array}$} \\
\hline
\end{tabular}

our calf-level estimates and estimates from other studies may be due to the influence of some larger operations in our sample. For example, the $\mathrm{HC}$ operation contributing the most to the weighted average diarrhea morbidity reported $60 \%$ diarrhea morbidity at the operation level; when this operation was omitted from the weighted calf level estimates, diarrhea morbidity declined to $30 \%$. Therefore, when comparing metrics among calf ranches or comparing calf ranches to the industry, the median demographic estimates at the operation level may be the most appropriate option.

\section{Antimicrobial Use}

The operation median percentage of preweaned calves on $\mathrm{HC}$ and $\mathrm{MC}$ operations with diarrhea that were treated with an antibiotic was $83 \%$ (Table 3 ). At the calf level, $62 \%$ of calves on $\mathrm{HC}$ operations with diarrhea received an antibiotic compared with $74.5 \%$ of diarrheic heifer calves on US dairy operations in 2006 (USDA, 2008a). The median operation surveyed reported that $50 \%$ of calves treated with an antibiotic for diarrhea received more than one type of antibiotic. At the calf level, $36 \%$ of calves receiving an antibiotic for diarrhea received more than one type of antibiotic. Our results suggest that characteristics of antibiotic use on $\mathrm{HC}$ and MC operations mirror that of US dairy operations.

The operation median treatment rate with an antibiotic for respiratory disease was 100\% (Table 3), whereas at the calf level, $96 \%$ of calves with respiratory disease received an antibiotic on $\mathrm{HC}$ operations. On US dairy operations, an estimated $93.4 \%$ of heifer calves with respiratory disease received an antibiotic (USDA, 2008a). The median operation reported that $47 \%$ of calves treated with an antibiotic for respiratory disease received more than one type of antibiotic. Although our finding suggests that polymicrobial therapy may not be uncommon in individual calves, some caution in this interpretation is advised. The term "antibiotic" was not defined and a list of antibiotics from which to choose was not given to respondents. As a result, respondents may have unintentionally misclassified therapies such as nonsteroidal antiinflammatory drugs as antibiotics, thereby overestimating the true level of antibiotic use. In addition, no attempt was made to delineate use of multiple antibiotics for a single condition (e.g., diarrhea) versus multiple conditions (e.g., diarrhea and respiratory disease) so multiple antibiotic use may indicate treatment of multiple concurrent diseases.

Medicated milk replacer use on $\mathrm{HC}$ and MC operations $(56 \%$, Table 4) was similar to that on US dairy operations (57.5\%; USDA, 2007) and higher than estimates obtained from Washington State (22.2 to 27.5\%; Raymond et al., 2006) and dairy herds across Michigan, Minnesota, New York, and Wisconsin (49.5\%; Zwald et al., 2004). Fifty-four percent of operations reported using antibiotics for preventing diarrhea or respiratory disease. Among operations with a policy of preventive 
Table 4. Operation-type-specific antibiotic use demographics of preweaned calf rearing operations in 2006

\begin{tabular}{|c|c|c|c|c|c|c|c|c|}
\hline \multirow[b]{2}{*}{ Respondent characteristic } & \multicolumn{6}{|c|}{ Operation type ${ }^{1}$} & \multirow{2}{*}{$\begin{array}{c}\text { Responses }^{2} \\
(\mathrm{n})\end{array}$} & \multirow[b]{2}{*}{$P$-value ${ }^{3}$} \\
\hline & $\mathrm{n}$ & $\%$ & $\mathrm{n}$ & $\%$ & $\mathrm{n}$ & $\%$ & & \\
\hline Used medicated milk replacer & 26 & 54 & 23 & 59 & 49 & 56 & 87 & 0.653 \\
\hline Antibiotics were given for preventing diarrhea or respiratory disease ${ }^{4}$ & 23 & 48 & 24 & 62 & 47 & 54 & 87 & 0.205 \\
\hline Written antibiotic protocols or usage guidelines were available & 29 & 60 & 27 & 71 & 56 & 65 & 86 & 0.304 \\
\hline
\end{tabular}

${ }^{1}$ Operation type: $\mathrm{HC}=$ preweaned heifer calves only; $\mathrm{MC}=$ preweaned heifer and bull calves; Overall includes HC and MC.

${ }^{2}$ Total number of $\mathrm{HC}$ and $\mathrm{MC}$ operations responding to a given question.

${ }^{3}$ All $P$-values are for the comparison of $\mathrm{HC}$ and MC operations.

${ }^{4}$ Preventive antibiotic use included use of medicated milk replacer if it was specifically given for preventive purposes.

${ }^{5} P$-values are derived from Fisher's exact test.

antibiotic use, antibiotics were administered for a median of $7 \mathrm{~d}$, representing $17 \%$ of the preweaning period. These findings suggest that when antibiotics are used for preventing diarrhea and respiratory disease in preweaned calves, calf ranches tend to target use within a specific period of increased risk of disease. Metaphylactic use of antibiotics has been shown to decrease morbidity in dairy-beef calves on a calf ranch (Berge et al., 2005).

Written antibiotic use protocols can help promote consistency in health care delivery, thereby reducing errors (Raymond et al., 2006). Approximately twothirds of $\mathrm{HC}$ and $\mathrm{MC}$ operations (65\%) had written antibiotic treatment guidelines available. In contrast, written protocols for treating common medical conditions were present on only $27 \%$ of Washington State dairy operations surveyed (Raymond et al., 2006), 21\% of Pennsylvania dairy operations surveyed (Sawant et al., 2005), and $32 \%$ of South Carolina dairy operations (Friedman et al., 2007). Our finding suggests that calf ranches may utilize written antibiotic use guidelines more frequently than dairy farms. Antibiotic treatment information was collected for individual calves on $90 \%$ of $\mathrm{MC}$ operations versus $71 \%$ of $\mathrm{HC}$ operations $(P=$ 0.036).

Fifty-six percent of $\mathrm{HC}$ and $\mathrm{MC}$ operations identified chronically ill calves and ceased antibiotic treatment, although the proportion of calves considered chronic (1\%) was minimal (Table 4). Identification of chronically ill animals is a first step in their removal, which may improve overall herd health by removing a source of pathogens for healthy animals (McGuirk, 2004), thereby positively affecting animal well-being and welfare. Results of a study of heifer calves in New York State herds suggest that improvements in average daily gain might be made by reducing the occurrence of chronic pneumonia (Virtala et al., 1996a). Measuring biological risk and optimizing the decision-making process regarding chronic individual cases deserves further study.

\section{Herd-Level Biosecurity and Biocontainment Practices}

Calf. Assuring adequate colostral IgG intake is generally regarded as the single most important management activity to minimize disease in early calf life. Representing $78 \%$ of all calves in the study, almost onehalf of calf ranches (46\%, Table 5) routinely measured passive immunity. The number of operations using this procedure is considerable given that only $2.1 \%$ of all US dairy operations ( $14.5 \%$ when restricted to large US herds) reported routine measurement of this important health risk factor (USDA, 2007). Given that calf ranches typically receive calves at or after $1 \mathrm{~d}$ of age, little opportunity exists to influence colostral transfer of IgG. Reasons why calf ranches favor measuring passive immunity might include assessing risk of illness and death for individual calves, monitoring colostrum management on client dairies, providing evidence during disease outbreak investigations, or determining rearing costs for a given client. Our finding suggests that calf ranches perceive utility in measuring passive immunity and appear to use this practice more frequently than dairy farms. With this information, they are positioned to anticipate disease problems and to favor dairy clients with excellent colostrum management and fewer ensuing losses.

Housing. Housing plays an important role in biosecurity and biocontainment (Anderson, 1998), with the central principle being to break transmission by preventing contact among individual calves (Reynolds, 2009). Individual pens or hutches are primarily used to house preweaned calves on $67.9 \%$ of US dairy opera- 
Table 5. Operation-type-specific biosecurity and biocontainment practices on preweaned calf rearing operations in 2006

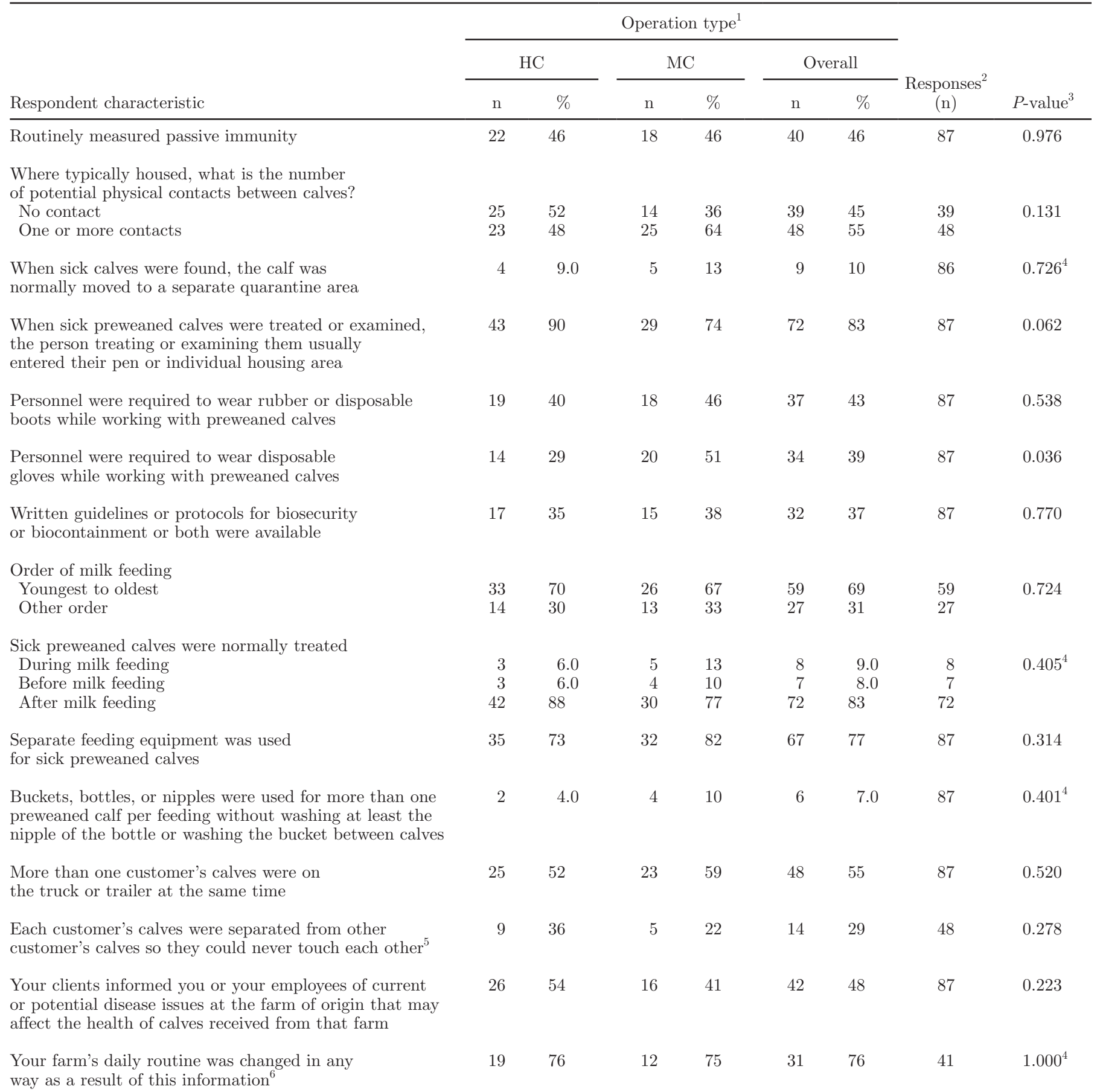

${ }^{1}$ Operation type: $\mathrm{HC}=$ preweaned heifer calves only; $\mathrm{MC}=$ preweaned heifer and bull calves; Overall includes HC and MC operation types.

${ }^{2}$ Total number of $\mathrm{HC}$ and $\mathrm{MC}$ operations responding to a given question.

${ }^{3} \mathrm{All} P$-values are for the comparison of $\mathrm{HC}$ and $\mathrm{MC}$ operations.

${ }^{4} P$-value derived from Fisher's exact test.

${ }^{5}$ Of those operations transporting multiple clients' calves simultaneously.

${ }^{6}$ Of those operations with knowledge of disease issues at the farm of origin that may affect calf health. 
tions (USDA, 2007). If individual pens are immediately adjacent or are constructed to allow direct contact, transmission of respiratory and gastrointestinal pathogens can occur (Barrington et al., 2002; Callan and Garry, 2002). Our work suggests that the majority $(55 \%$, Table 5$)$ of calf ranches house calves in a manner allowing one or more direct contacts. Future studies of dairy calf housing, in addition to noting the type of housing (e.g., hutch, individual pen or group), should enumerate the number of contacts allowed among calves when assessing relevant health and welfare outcomes.

Isolation. A suggested principle of biosecurity and biocontainment is to isolate calves that are sick from healthy herdmates for 3 or more weeks to avoid buildup of pathogens shed in the environment (Barrington et al., 2002). However, $90 \%$ of calf ranches did not remove sick calves to an isolation area (Table 5), and most respondents that removed sick calves returned them to the original location after the calves appeared healthy (67\%). In a French study, calves in herds with a policy of not isolating sick calves from healthy calves had twice the odds of morbidity between 1 and $15 \mathrm{~d}$ of age (Fourichon et al., 1997). Removal of calves from individual housing units may be impractical due to labor and facility constraints. Producers may feel that if sick calves are housed such that direct contact and the potential for fecal-oral transmission of pathogens are apparently minimized, then removal of sick calves is unnecessary. Housing features such as solid sidewalls or complete separation between housing units are important to help limit pathogen transmission (Barrington et al., 2002; Callan and Garry, 2002). Additionally, daily movement of personnel, including entering the animal pens to administer treatments, becomes more of a concern if ill animals are not isolated, because contact of personnel with adjacent healthy calves may facilitate pathogen transmission. This is important when considering that the housing unit was usually entered when examining or treating an individual calf on $83 \%$ of responding operations.

Personal Protective Equipment. The hygiene of hands and personal protective equipment such as coveralls and boots is an important tenet of biosecurity, particularly for gastrointestinal and respiratory disease (Barrington et al., 2002; Callan and Garry, 2002; Maunsell and Donovan, 2008). Fewer than half of $\mathrm{HC}$ and $\mathrm{MC}$ operations required boots $(43 \%)$ or gloves $(39 \%)$ when working with preweaned calves, suggesting that close scrutiny of these practices in future studies is warranted. It is known that feces, saliva, and nasal secretions pose a direct risk and can readily contain pathogens from the gastrointestinal and respiratory systems.
Biosecurity and Biocontainment Protocols. Protocols are important tools to help manage biosecurity, biocontainment, disease treatment, feeding, hygiene, and expectations of employees (Heath, 1992; BAMN, 2001; Barrington et al., 2002; Maunsell and Donovan, 2008) and should be written and available for review by calf ranch personnel (Maunsell and Donovan, 2008). Our study indicated that $37 \%$ of calf ranches had written plans in 2006 with the caveat that our estimates may not include biosecurity and biocontainment guidelines conveyed orally (Table 5).

Feeding Management. Whole or waste milk was used as the primary liquid feed source by $17 \%$ of calf ranches compared with $50.7 \%$ of US dairy operations (USDA, 2008b), with MC operations (12 of 39, $31 \%$ ) utilizing whole or waste milk more often than $\mathrm{HC}$ operations (3 of $48,6.0 \% ; P=0.003$ ). Waste milk may pose a biological risk to calves (Selim and Cullor, 1997; Godden et al., 2005; Moore et al., 2009) that can be reduced by pasteurization (Elizondo-Salazar et al., 2010). Feeding pasteurized waste milk has been associated in the short term with lower diarrhea and respiratory disease morbidity and increased preweaning and postweaning weight gain (Jamaluddin et al., 1996a,b; Godden et al., 2005). Most (87\%) HC and MC operations feeding primarily whole or waste milk used pasteurization compared with $5.9 \%$ of US dairy operations feeding some whole or waste milk to calves that used pasteurization (USDA, 2008b). Our data suggest most calf ranches feeding waste milk are cognizant of the inherent biological risk and take steps (i.e., pasteurization) to manage this risk.

Most operations (69\%) fed milk to calves in order from youngest to oldest (Table 5). Sick preweaned calves were treated after milk feeding on $83 \%$ of calf ranches surveyed. In contrast, a pilot study of dairies in 2 California counties found that $57.9 \%$ and $85.1 \%$ of dairies surveyed treated calves with medication during feeding (Lopez-Nieto et al., 1972). Treatment during feeding would appear to increase the opportunity for contamination of feeding equipment and indirect pathogen transmission. Our study found that sick preweaned calves were fed with separate equipment on over three-fourths of calf ranches $(77 \%)$. It has been suggested that salmonellosis may be spread readily through indirect mechanisms (Gardner et al., 2004), and one report suggested that $40 \%$ of secondary cases were due to routes other than spread via direct contact (Hardman et al., 1991).

Hygiene of shared equipment is an important element of biosecurity and biocontainment during the preweaning period (Barrington et al., 2002; Maunsell and Donovan, 2008). Current estimates of US dairy opera- 
tions indicate that feeding equipment was cleaned and disinfected between calves on $24.4 \%$ of operations and daily on $58.5 \%$ of operations in 2006 (USDA, 2007). Although our survey did not ask about disinfection of feeding equipment per se, our findings suggest that feeding equipment hygiene on calf ranches should be at least similar and probably superior to efforts on US dairy operations in that during feeding, $93 \%$ of operations did not use buckets, bottles, or nipples without washing between calves.

Records. Almost all (99\%) HC and MC operations surveyed uniquely identified calves and maintained records on individual calves. The most common information collected was mortality (92\% of operations), individual antibiotic treatments (79\% of operations), and morbidity ( $75 \%$ of operations). In contrast, one report indicated that of $63 \%$ of dairy operations keeping calf records, none kept sick calf treatment information (Goodger and Theodore, 1986). Another survey found that fewer than $12 \%$ of dairies kept calf health records with complete treatment information (Goodger et al., 1993). A third study reported that relatively few dairy herds $(36.3 \%)$ and organic herds $(34.4 \%)$ kept antibiotic treatment records for calves and heifers (Zwald et al., 2004). Failure to maintain diagnostic and treatment records greatly impedes herd disease problem solving and assessment of magnitude, duration, and cost of disease.

\section{Study Limitations}

The reader should bear in mind some limitations of this work. Our survey was cross-sectional, which precluded any temporal inferences. This survey was conducted at the herd-level so stated practices should be regarded as herd policies, rather than actual events experienced by individual calves, to avoid the "ecological fallacy" (Dohoo et al., 2009). Our goal was to be as inclusive as possible with our sampling frame; however, this frame may not be exhaustive and, to our knowledge, no all-inclusive list of calf rearing operations in the US exists. Although we cannot assess this bias with our data set, the reader should recognize the potential for bias insofar as the respondents may differ from the true population of calf ranches in the United States and that data from nonresponders may differ from that of responders. We asked respondents for estimates that were, by nature, retrospective and self-reported and as such, these estimates may be based either on recall or review of records, either of which might be subject to recall bias or information bias. Misclassification bias may have occurred in some responses because case definitions of common preweaning period diseases and terms such as "antibiotic" were not specifically defined.
In addition, the reader should bear in mind the potential limitations of comparing retrospective estimates to the available prospective estimates in the literature.

\section{CONCLUSIONS}

Calf ranches are generally similar and in some aspects superior to US dairy operations in morbidity, mortality, antibiotic use practices, and biosecurity and biocontainment practices. Calf ranches used more generally accepted biosecurity and biocontainment practices than typical commercial dairy operations and we surmise that operations rearing preweaned calves may benefit further from use of additional biosecurity practices. These data provide initial estimates of benchmark metrics at the operation level that should prove useful in the evaluation of calf ranches. Future work with calf ranches should focus on prospectively collecting data on morbidity, mortality, antibiotic use, biosecurity, biocontainment, and other management procedures experienced at the individual calf level.

\section{REFERENCES}

Anderson, J. F. 1998. Biosecurity: A new term for an old conceptHow to apply it. Bovine Pract. 32:61-70.

BAMN. 2001. Biosecurity of dairy farm feedstuffs. Pages 1-5 in Bovine Alliance on Management and Nutrition. Bovine Alliance on Management and Nutrition (BAMN), Arlington, VA.

Barrington, G. M., J. M. Gay, and J. F. Evermann. 2002. Biosecurity for neonatal gastrointestinal diseases. Vet. Clin. North Am. Food Anim. Pract. 18:7-34.

Berge, A. C., P. Lindeque, D. A. Moore, and W. M. Sischo. 2005. A clinical trial evaluating prophylactic and therapeutic antibiotic use on health and performance of preweaned calves. J. Dairy Sci. 88:2166-2177.

Callan, R. J., and F. B. Garry. 2002. Biosecurity and bovine respiratory disease. Vet. Clin. North Am. Food Anim. Pract. 18:57-77.

Dillman, D. A. 2007. Mail and Internet Surveys-The Tailored Design Method. 2nd ed. John Wiley \& Sons Inc., Hoboken, NJ.

Dohoo, I., W. Martin, and H. Stryhn. 2009. Ecological and group-level studies. Pages 773-788 in Veterinary Epidemiologic Research. 2nd ed. S. M. McPike, ed. VER Inc., Charlottetown, Prince Edward Island, Canada.

Donovan, G. A., I. R. Dohoo, D. M. Montgomery, and F. L. Bennett. 1998. Associations between passive immunity and morbidity and mortality in dairy heifers in Florida, USA. Prev. Vet. Med. 34:31-46.

Elizondo-Salazar, J. A., C. M. Jones, and A. J. Heinrichs. 2010. Evaluation of calf milk pasteurization systems on 6 Pennsylvania dairy farms. J. Dairy Sci. 93:5509-5513.

Fourichon, C., F. Beaudeau, and H. Seegers. 1997. Critical points related to housing and management control programmes for calf morbidity and mortality in French dairy herds. Pages 37-40 in Proc. 9th Int. Congr. Anim. Hyg. International Society for Animal Hygiene, Helsinki, Finland.

Friedman, D. B., C. P. Kanwat, M. L. Headrick, N. J. Patterson, J C. Neely, and L. U. Smith. 2007. Importance of prudent antibiotic use on dairy farms in South Carolina: A pilot project on farmers' knowledge, attitudes and practices. Zoonoses Public Health 54:366-375.

Gardner, C. E., D. V. Nydam, R. G. Ellis, S. Kelsey, P. L. McDonough, and L. D. Warnick. 2004. Case report-Management of an out- 
break of salmonellosis on a commercial calf raising unit. Bovine Pract. 38:147-154.

Godden, S. M., J. P. Fetrow, J. M. Feirtag, L. R. Green, and S. J. Wells. 2005. Economic analysis of feeding pasteurized nonsaleable milk versus conventional milk replacer to dairy calves. J. Am. Vet. Med. Assoc. 226:1547-1554.

Goodger, W. J., and E. M. Theodore. 1986. Calf management practices and health management decisions on large dairies. J. Dairy Sci. 69:580-590.

Goodger, W. J., F. Troutt, L. Wallace, and C. Williams. 1993. Management factors affecting antibiotic residues and the establishment of antibiotic resistance in dairy calves. Bovine Pract. 27:135-140.

Hardman, P. M., C. M. Wathes, and C. Wray. 1991. Transmission of salmonellae among calves penned individually. Vet. Rec. 129:327329.

Heath, S. E. 1992. Neonatal diarrhea in calves: Diagnosis and intervention in problem herds. Compend. Contin. Educ. Vet. 14:995-1002.

Jamaluddin, A. A., T. E. Carpenter, D. W. Hird, and M. C. Thurmond. 1996a. Economics of feeding pasteurized colostrum and pasteurized waste milk to dairy calves. J. Am. Vet. Med. Assoc. 209:751-756

Jamaluddin, A. A., D. W. Hird, M. C. Thurmond, and T. E. Carpenter. 1996b. Effect of preweaning feeding of pasteurized and nonpasteurized milk on postweaning weight gain of heifer calves on a Californian dairy. Prev. Vet. Med. 28:91-99.

Lopez-Nieto, E., G. Crenshaw, C. E. Franti, and A. D. Wiggins. 1972. A San Joaquin and Tulare County study of diarrhea in dairy calves. Calif. Agric. 26:6-9.

Maunsell, F., and G. A. Donovan. 2008. Biosecurity and risk management for dairy replacements. Vet. Clin. North Am. Food Anim. Pract. 24:155-190.

McGuirk, S. M. 2004. Trouble shooting calf health concerns. Med. Vet. Québec 34:19-21.

Moore, D. A., W. M. Sischo, D. M. Festa, J. P. Reynolds, E. R. Atwill and C. A. Holmberg. 2002. Influence of arrival weight, season and calf supplier on survival in Holstein beef calves on a calf ranch in California, USA. Prev. Vet. Med. 53:103-115.

Moore, D. A., J. Taylor, M. L. Hartman, and W. M. Sischo. 2009. Quality assessments of waste milk at a calf ranch. J. Dairy Sci. 92:3503-3509.

Raymond, M. J., R. D. Wohrle, and D. R. Call. 2006. Assessment and promotion of judicious antibiotic use on dairy farms in Washington State. J. Dairy Sci. 89:3228-3240.

Reynolds, J. 2009. Troubleshooting biosecurity problems. Pages 213 218 in Proc. 13th Annual DCHA Dairy Calf and Heifer Conf. Dairy Calf and Heifer Association, Chesterfield, MO.

Sawant, A. A., L. M. Sordillo, and B. M. Jayarao. 2005. A survey on antibiotic usage in dairy herds in Pennsylvania. J. Dairy Sci. 88:2991-2999.
Selim, S. A., and J. S. Cullor. 1997. Number of viable bacteria and presumptive antibiotic residues in milk fed to calves on commercial dairies. J. Am. Vet. Med. Assoc. 211:1029-1035.

Sivula, N. J., T. R. Ames, W. E. Marsh, and R. E. Werdin. 1996. Descriptive epidemiology of morbidity and mortality in Minnesota dairy heifer calves. Prev. Vet. Med. 27:155-171.

Tyler, J. W., D. D. Hancock, S. E. Wiksie, S. L. Holler, J. M. Gay, and C. C. Gay. 1998. Use of serum protein concentration to predict mortality in mixed-source dairy replacement heifers. J. Vet. Intern. Med. 12:79-83.

USDA. 1993. Dairy herd management practices focusing on preweaned heifers, April 1991-July 1992. USDA-APHIS-VS, CEAH, Fort Collins, CO.

USDA. 1994. Dairy heifer morbidity, mortality, and health management focusing on preweaned heifers, April 1991-July 1992. USDAAPHIS-VS, CEAH, Fort Collins, CO.

USDA. 1996. Dairy 1996, Part I: Reference of 1996 Dairy Management Practices. USDA-APHIS-VS, CEAH, Fort Collins, CO.

USDA. 2002. Dairy 2002, Part I: Reference of Dairy Health and Health Management in the United States, 2002. USDA-APHISVS, CEAH, Fort Collins, CO.

USDA. 2007. Dairy 2007, Part I: Reference of dairy cattle health and management practices in the United States, 2007. USDA-APHISVS, CEAH, Fort Collins, CO.

USDA. 2008a. Dairy 2007, Part III: Reference of dairy cattle health and management practices in the United States, 2007. USDAAPHIS-VS, CEAH, Fort Collins, CO.

USDA. 2008b. Special tabulation-Liquid feeds: Dairy 2007, Part I: Reference of dairy cattle health and management practices in the United States, 2007. USDA-APHIS-VS, CEAH, Fort Collins, CO.

Virtala, A. M., G. D. Mechor, Y. T. Grohn, and H. N. Erb. 1996a The effect of calfhood diseases on growth of female dairy calves during the first 3 months of life in New York State. J. Dairy Sci. 79:1040-1049.

Virtala, A. M., G. D. Mechor, Y. T. Grohn, H. N. Erb, and E. J. Dubovi. 1996b. Epidemiologic and pathologic characteristics of respiratory tract disease in dairy heifers during the first three months of life. J. Am. Vet. Med. Assoc. 208:2035-2042.

Virtala, A. M. K., G. D. Mechor, Y. T. Grohn, and H. N. Erb. 1996c. Morbidity from nonrespiratory diseases and mortality in dairy heifers during the first three months of life. J. Am. Vet. Med. Assoc. 208:2043-2046.

Wolf, C. A. 2003. Custom dairy heifer grower industry characteristics and contract terms. J. Dairy Sci. 86:3016-3022.

Zwald, A. G., P. L. Ruegg, J. B. Kaneene, L. D. Warnick, S. J. Wells, C. Fossler, and L. W. Halbert. 2004. Management practices and reported antimicrobial usage on conventional and organic dairy farms. J. Dairy Sci. 87:191-201. 